\title{
Parental, fetal, and infant risk factors for preschool overweight: the Generation R Study
}

\author{
Denise H.M. Heppe ${ }^{1-3}$, Jessica C. Kiefte-de Jong ${ }^{1,3}$, Büşra Durmuşs ${ }^{1-3}$, Henriëtte A. Moll ${ }^{3}$, Hein Raat ${ }^{4}$, Albert Hofman ${ }^{2}$ \\ and Vincent W.V. Jaddoe ${ }^{1-3}$
}

BACKGROUND: Overweight has its origins largely in early life. We aimed to identify the most important parental, fetal, and infant risk factors of preschool overweight.

METHODS: In a prospective cohort study, among 3,610 Caucasian preschool children, we assessed the associations of 34 putative parental, fetal, and infant factors with overweight risk.

RESULTS: Higher maternal BMI, paternal BMI, and birth weight were associated with higher risk of preschool overweight (odds ratio (OR): 1.23, 95\% confidence interval (Cl): 1.10, 1.39; OR: 1.35, 95\% Cl: 1.19, 1.53; and OR: 2.71, 95\% Cl: 2.27, 3.25, respectively, per SD increase). The same model identified low household income (OR: 1.74, 95\% Cl: 1.24, 2.45), being female (OR: 1.55, 95\% Cl: 1.20, 2.01), and experiencing third-trimester accelerated growth (OR: 1.73, 95\% Cl: 1.24, 2.40) or postnatal accelerated growth (OR: 6.39, 95\% Cl: 4.54, 8.99) as risk factors for preschool overweight. Higher polyunsaturated fat intake at 14 mo was associated with a lower risk of preschool overweight (OR: 0.77, 95\% Cl: 0.62, 0.96 per SD).

CONCLUSION: Parental anthropometrics and household income, fetal and infant accelerated growth, and infant dietary fat intake are the major risk factors for the development of preschool overweight. Further studies need to explore whether these risk factors could be potential targets for preventive interventions.

O verweight is a major public health problem (1). Childhood overweight is a well-documented risk factor for various adverse health outcomes in childhood and adulthood (2). Because childhood overweight tends to track into adulthood, prevention should focus on risk factors for overweight in early life (3). Numerous studies have identified associations of individual risk factors with childhood overweight (4). However, the development of childhood overweight is not due to one individual risk factor but results from interacting genetic, behavioral, and environmental risk factors. Few studies have considered the relative impact of these individual risk factors by simultaneous assessment (5-14). These studies suggested that infant growth rates are the strongest risk factor for overweight $(8,11,12)$. Infant and fetal growth rates are highly inversely correlated (15). Decelerated fetal growth in the second or third trimester and accelerated fetal growth in the third trimester have been associated with a higher fat mass percentage at 6 mo of age (16). However, not much is known about the relative effect of fetal growth on the risk of overweight because none of the earlier studies that simultaneously assessed risk factors for overweight considered fetal growth. Simultaneous assessment of risk factors, including fetal growth, is needed to clarify which determinants are the most important in overweight development. Identification of independent risk factors in infancy and especially in fetal life may help to design childhood overweight prevention strategies focused on the earliest phase of life.

Therefore, in a population-based prospective cohort study of 3,610 mothers, fathers, and their children, we assessed the independent associations of parental, fetal, and infant risk factors with the risk of preschool-age overweight.

\section{RESULTS}

\section{Subject Characteristics}

The prevalence of overweight, including obesity, in boys and girls was 7.1 and $11.4 \%$, respectively. Obesity was prevalent in 1.6 and $1.3 \%$ of the boys and girls. As compared with normalweight children, overweight children had fathers who were heavier. Moreover, their mothers were heavier and gained more weight during pregnancy, were younger and lower educated, smoked more often, used alcohol or folic acid supplements less often, and had a lower household income (Table 1). As compared with normal-weight children, overweight children more frequently had experienced fetal or infant accelerated growth and had a higher birth weight. Overweight children were also more often introduced to solid foods before the age of 6 mo.

\section{Risk Factors of Preschool Overweight}

Children living in a family with a household income $<€ 2,200$ ( $\sim$ US $\$ 2,855)$ per month were more likely to be overweight at preschool age, as compared with children in a family with a household income $\geq € 2,200$ per month (odds ratio (OR): 1.74, 95\% confidence interval (CI): 1.24, 2.45) (Table 2). Higher maternal prepregnancy BMI and paternal BMI were associated with an increased risk of overweight (OR: 1.23, 95\% CI: 1.10, 1.39 and OR: $1.35,95 \%$ CI: 1.19, 1.53 per 1 SD increase, respectively). 


\section{Risk factors for preschool overweight}

Articles

Table 1. Characteristics of the normal-weight and overweight study population, the Generation R Study, Rotterdam, The Netherlands

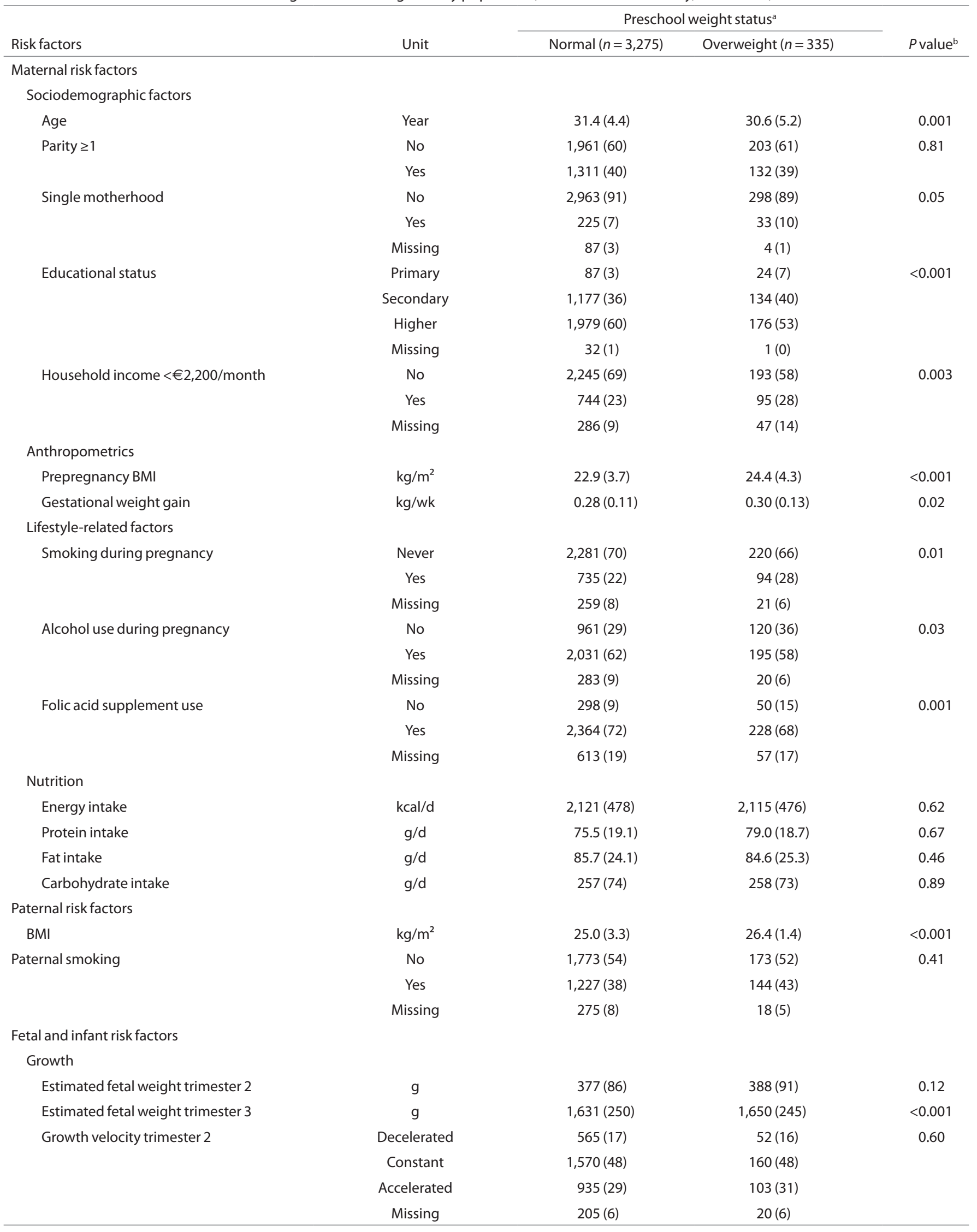

Table 1 Continued on next page 


\section{Articles $\mid$ Heppe et al.}

Table 1. Continued

\begin{tabular}{|c|c|c|c|c|}
\hline \multirow[b]{2}{*}{ Risk factors } & \multirow[b]{2}{*}{ Unit } & \multicolumn{2}{|c|}{ Preschool weight status ${ }^{\mathrm{a}}$} & \multirow[b]{2}{*}{$P$ value ${ }^{b}$} \\
\hline & & Normal $(n=3,275)$ & Overweight $(n=335)$ & \\
\hline \multirow[t]{3}{*}{ Growth velocity trimester 3} & Decelerated & $807(25)$ & $89(27)$ & \multirow[t]{3}{*}{$<0.001$} \\
\hline & Accelerated & $591(18)$ & $89(27)$ & \\
\hline & Missing & $69(2)$ & $4(1)$ & \\
\hline \multirow[t]{2}{*}{ Gender } & Male & $1,672(51)$ & $128(38)$ & \multirow[t]{2}{*}{$<0.001$} \\
\hline & Female & $1,603(49)$ & $207(62)$ & \\
\hline \multirow[t]{2}{*}{ Growth velocity birth to $2 y$} & Decelerated & $813(25)$ & $146(9)$ & \multirow[t]{2}{*}{$<0.001$} \\
\hline & Constant & $1,350(41)$ & $115(34)$ & \\
\hline \multirow[t]{3}{*}{ Breast-feeding } & No & $302(9)$ & $27(8)$ & \multirow[t]{3}{*}{0.61} \\
\hline & Yes & $2,823(86)$ & $281(84)$ & \\
\hline & Missing & $150(5)$ & $27(8)$ & \\
\hline \multirow[t]{3}{*}{ Introduction of fruits and vegetables } & $<6 \mathrm{mo}$ & $2,253(69)$ & $222(63)$ & \multirow[t]{3}{*}{0.02} \\
\hline & $\geq 6 \mathrm{mo}$ & $303(9)$ & $16(5)$ & \\
\hline & Missing & $719(22)$ & $97(29)$ & \\
\hline Energy intake at $14 \mathrm{mo}$ & $\mathrm{kcal} / \mathrm{d}$ & $1,309(283)$ & $1,300(273)$ & 0.19 \\
\hline Protein intake at 14 mo & $g / d$ & $41.7(11.6)$ & $42.0(12.1)$ & 0.72 \\
\hline Fat intake at 14 mo & $g / d$ & $41.7(15.9)$ & $39.4(15.7)$ & 0.06 \\
\hline \multirow{2}{*}{ Day care at age 2} & $>3 \mathrm{~d} / \mathrm{wk}$ & $514(16)$ & $51(15)$ & \multirow{2}{*}{0.35} \\
\hline & Missing & $728(22)$ & $93(28)$ & \\
\hline \multirow[t]{3}{*}{ TV watching at age 2} & Yes & $2,588(79)$ & $246(73)$ & \multirow[t]{3}{*}{0.93} \\
\hline & Never & $175(5)$ & $17(5)$ & \\
\hline & Missing & $512(16)$ & $72(22)$ & \\
\hline
\end{tabular}

Values reflect the mean (SD) for continuous variables or absolute number (percentage) for categorical variables.

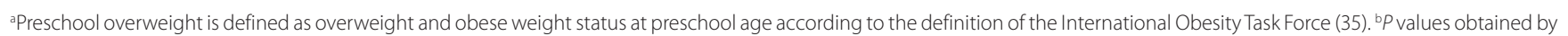
Student's $t$-tests for continuous variables and $\chi^{2}$ tests for categorical variables.

Maternal smoking during pregnancy and low maternal education showed a borderline significant association with higher risk of preschool overweight $(P=0.10$ and $P=0.09)$. Paternal smoking and maternal intakes of proteins and carbohydrates, parity, and alcohol or folic acid use were not independently associated with the risk of preschool overweight.

Higher birth weight and female gender were associated with an increased risk of preschool overweight (OR: 2.71, 95\% CI: 2.27, 3.25 per 1 SD increase and OR: $1.55,95 \%$ CI: $1.20,2.01$, respectively). As compared with normal growth, both thirdtrimester fetal accelerated growth and infant accelerated growth were associated with an increased risk of preschool overweight
(OR: 1.73, 95\% CI: 1.24, 2.40 and OR: 6.39, 95\% CI: 4.54, 8.99, respectively). Third-trimester fetal decelerated growth showed a borderline significant association with higher risk of preschool overweight $(P=0.08)$. Introduction of solid foods after the age of $6 \mathrm{mo}$, as compared with before the age of $6 \mathrm{mo}$, was associated with a lower risk of preschool overweight (OR: 0.45, 95\% CI: $0.24,0.84)$. A higher fat intake at the age of 14 mo was associated with a lower risk of preschool overweight (OR: 0.88, 95\% CI: 0.78, 0.99 per $100 \mathrm{kcal}$ increase of energy intake from fat). We further explored this association by separately analyzing intakes of saturated fat, monounsaturated fat, and polyunsaturated fats (PUFAs) (Table 3), which revealed that only PUFA intake, but 
Table 2. Associations of maternal, paternal, fetal, and childhood risk factors for preschool overweight, the Generation R Study, Rotterdam, The Netherlands

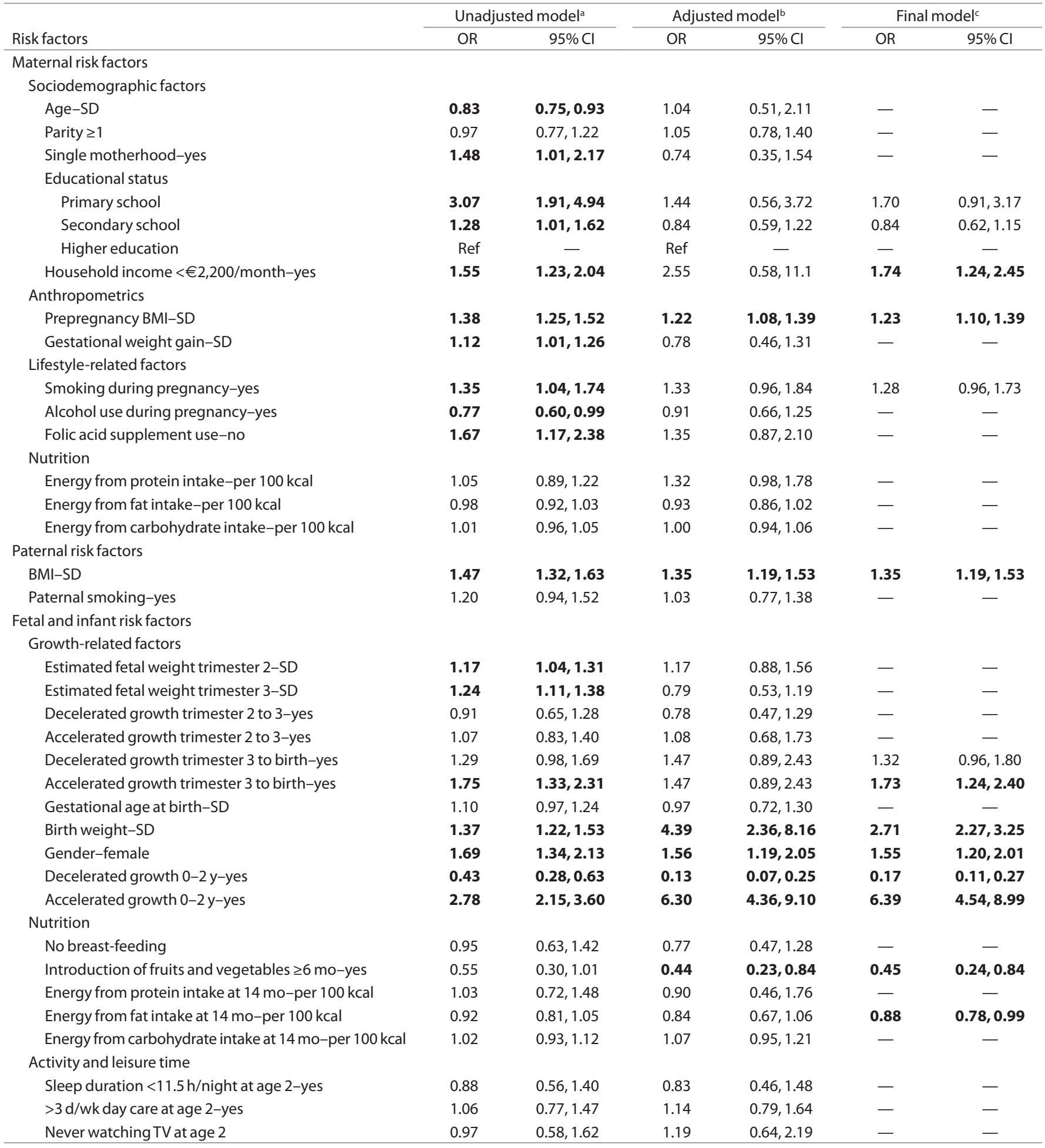

Preschool overweight is defined as overweight and obese weight status at preschool age according to the definition of the International Obesity Task Force (35). Boldfaced font denotes a $P$ value $<0.05$.

$\mathrm{Cl}$, confidence interval; OR, odds ratio.

aValues are based on univariate logistic regression models and reflect the odds ratio and $95 \% \mathrm{Cl}$ for the risk of preschool overweight for each parental or child characteristic. ${ }^{b}$ Values are based on a logistic regression model including all variables and reflect the odds ratio and $95 \% \mathrm{Cl}$ for the risk of preschool overweight for each parental or child characteristic. We added the interaction of single motherhood with age, of maternal education with age, of family income with age, of gestational weight gain with age, of maternal fat intake with gestational weight gain, of maternal education with family income, of maternal smoking with birth weight, and of birth weight with postnatal catch-down/up growth to the model. The model was additionally adjusted for the time difference between the ultrasound measurements at trimesters 2 and 3 , and the time difference between the ultrasound measurement at trimester 3 and the gestational age at birth. Values are based on a logistic regression model using stepwise backward selection and reflect the odds ratio and $95 \% \mathrm{Cl}$ for the risk of preschool overweight for each parental or child characteristic that remained in the backward selection model $(P<0.10)$. The interactions of single motherhood with age and of maternal fat intake with gestational weight gain remained in the model. 
not saturated fat or monounsaturated fat intake, was inversely associated with the risk of preschool overweight $(P=0.03)$. Infant breast-feeding, television (TV) watching, attending day care, and sleep duration were not independently associated with preschool overweight. Time difference between fetal growth measurements did not significantly contribute to the explained variance of the final model.

Older maternal age was found to lower the risk of preschool overweight in single mothers $(P=0.01)$ but not in mothers

Table 3. Fat intake of child at 14 mo of age and the risk of preschool overweight, the Generation R Study, Rotterdam, The Netherlands

\begin{tabular}{lcccc}
\hline & \multicolumn{2}{c}{ Unadjusted model ${ }^{\mathrm{a}}$} & \multicolumn{2}{c}{ Final model $^{\mathrm{b}}$} \\
\cline { 2 - 6 } Risk factors & OR & $95 \% \mathrm{Cl}$ & $\mathrm{OR}$ & $95 \% \mathrm{Cl}$ \\
\hline $\begin{array}{l}\text { Fat intake of the child at } 14 \mathrm{mo} \\
\text { motal fats-SD }\end{array}$ & 0.88 & $0.75,1.03$ & $\mathbf{0 . 8 3}$ & $\mathbf{0 . 7 0 , 0 . 9 9}$ \\
$\quad \begin{array}{l}\text { Saturated fats-SD } \\
\quad\end{array}$ & 0.95 & $0.81,1.12$ & 1.04 & $0.78,1.37$ \\
$\quad \begin{array}{l}\text { Monounsaturated } \\
\text { fats-SD }\end{array}$ & 0.90 & $0.77,1.06$ & 0.95 & $0.65,1.38$ \\
$\begin{array}{l}\text { Polyunsaturated } \\
\text { fats-SD }\end{array}$ & 0.86 & $0.73,1.01$ & $\mathbf{0 . 7 7}$ & $\mathbf{0 . 6 2 , 0 . 9 6}$
\end{tabular}

Preschool overweight is defined as overweight and obese weight status at preschool age according to the definition of the International Obesity Task Force (35). Boldfaced font denotes a $P$ value $<0.05$

$\mathrm{Cl}$, confidence interval; OR, odds ratio.

values are based on univariate logistic regression models and reflect the odds ratio and 95\% Cl for the risk of preschool overweight for each level of fat intake at 14 mo of age. bValues are based on a logistic regression model using stepwise backward selection and reflect the odds ratio and $95 \% \mathrm{Cl}$ for the risk of preschool overweight for each level of fat intake at 14 mo of age. Models were adjusted for household income, maternal BMI, educational level and smoking, paternal BMI, fetal decelerated and accelerated growth in the third trimester, infant birth weight, gender, postnatal decelerated and accelerated growth, age at introduction of solid foods, the interaction of single motherhood with age, and of maternal fat intake with gestational weight gain, and the other fat intakes.

Table 4. Interactions between maternal and infant risk factors for preschool overweight, the Generation R Study, Rotterdam, The Netherlands

\begin{tabular}{|c|c|c|c|c|c|}
\hline & & \multicolumn{2}{|c|}{ Unadjusted model ${ }^{\mathrm{a}}$} & \multicolumn{2}{|c|}{ Final model ${ }^{b}$} \\
\hline \multicolumn{2}{|c|}{ Interaction } & OR & $95 \% \mathrm{Cl}$ & OR & $95 \% \mathrm{Cl}$ \\
\hline $\begin{array}{l}\text { Maternal } \\
\text { age }\end{array}$ & $\begin{array}{c}\text { Single } \\
\text { motherhood }\end{array}$ & & & & \\
\hline \multirow[t]{2}{*}{ Age-SD } & No & 0.91 & $0.80,1.03$ & 1.02 & $0.88,1.19$ \\
\hline & Yes & 0.64 & $0.47,0.85$ & 0.56 & $0.36,0.88$ \\
\hline $\begin{array}{l}\text { Gestational } \\
\text { weight gain }\end{array}$ & $\begin{array}{l}\text { Maternal fat } \\
\text { intake }(g / d)\end{array}$ & & & & \\
\hline \multirow{3}{*}{$\begin{array}{l}\text { Weight } \\
\text { gain-SD }\end{array}$} & Tertile 1 & 1.02 & $0.84,1.23$ & 1.00 & $0.79,1.26$ \\
\hline & Tertile 2 & 1.13 & $0.90,1.42$ & 1.11 & $0.89,1.39$ \\
\hline & Tertile 3 & 1.25 & $0.94,1.67$ & 1.27 & $0.93,1.72$ \\
\hline
\end{tabular}

Boldfaced font denotes a $P$ value $<0.05$.

$\mathrm{Cl}$, confidence interval; OR, odds ratio.

a Values are based on univariate logistic regression models and reflect the OR and 95\% CI for the risk of preschool overweight for the interacting risk factors. ${ }^{b}$ Values are based on a logistic regression model using stepwise backward selection and reflect the OR and 95\% Cl for the risk of preschool overweight for the interacting risk factors. Models were adjusted for household income, maternal BMI, educational level and smoking, paternal BMI, fetal decelerated and accelerated growth in the third trimester, infant birth weight, gender, postnatal decelerated and accelerated growth, age at introduction of solid

foods, fat intake at age $13 \mathrm{mo}$, and the other interaction. who were not single $(P=0.77)$ (Table 4$)$. In mothers who were in the highest tertile of daily fat intake, gestational weight gain tended to be a stronger risk factor for preschool overweight as compared with gestational weight gain in mothers with lower daily fat intakes. However, in stratified analysis this association was not significant $(P=0.12)$. After Bonferroni correction, all findings from the backward model remained significant, with the exception of the association of infant fat intake at the age of 14 mo with a lower risk of overweight.

\section{DISCUSSION}

\section{Main Findings}

In this prospective cohort study in the Netherlands, we found that low family household income, high maternal and paternal BMI, female gender, higher birth weight, and both fetal and infant accelerated growth were associated with increased risk of preschool overweight. Late introduction of solid foods and infant intake of PUFA were associated with a reduced risk of preschool overweight. In single mothers, older age was found to reduce the risk of preschool overweight.

\section{Strengths and Limitations}

To our knowledge, this is the first study that simultaneously assessed the influence of maternal, paternal, fetal, and infant risk factors on preschool overweight. The strength of this study is that we prospectively collected detailed information on many potential risk factors. Mothers in our study population were relatively highly educated; $60 \%$ finished higher education, as compared with $31 \%$ in the study area (17). This difference may be largely due to restriction of the study population to Caucasian participants. Moreover, mothers of children who lacked data on preschool weight status more often had a low educational attainment. In these children, exposure to risk factors for overweight was higher and birth weight lower. If selective participation has influenced our results, it might more likely have weakened than strengthened our results; however, this cannot be excluded. Our results should therefore be carefully generalized to other populations. Nevertheless, the overweight prevalence in our study population was comparable with that in the study area: 7.1 and $11.4 \%$ in boys and girls, respectively, in our study population as compared with 6.4 and $11.9 \%$ in 3-6-year-old Dutch boys and girls, respectively, in the study area (18).

\section{Comparison With Other Studies}

Our results showed that both higher fetal and infant growth rates lead to preschool overweight. The independent effect of infant accelerated growth on overweight risk is well established $(5,8,11,12)$. However, to our knowledge, the effect of fetal growth, independent of other risk factors, has not been studied yet. In an earlier study within a subgroup of our cohort, both third-trimester decelerated and accelerated growth were associated with a higher fat mass at the age of 6 mo (16). In a small study of 58 twins, high fetal growth velocity was not associated with adiposity in adulthood (19). The thrifty phenotype hypothesis proposed that fetal growth restriction in early pregnancy leads to metabolic adaptations (20), which have beneficial effects 
in the short term but predispose to adiposity and type 2 diabetes in the long term. Accelerated fetal growth may be an early consequence of these adaptations, resulting in increased risk of adiposity in later life. More research is needed to further explore the independent consequences of decelerated or accelerated fetal growth in the development of overweight.

Our finding that maternal prepregnancy BMI is associated with overweight in preschoolers is in line with previous studies $(5-9,14)$. In two studies among preschoolers that took paternal BMI into account, paternal BMI was associated with overweight, independent of maternal BMI $(8,9)$. Parental anthropometrics may affect childhood overweight by shared genetic, environmental, and behavioral mechanisms.

In single mothers, older age decreased the risk of preschool overweight. This interaction was not reported in earlier studies. Single motherhood has been suggested to be a risk factor for childhood overweight in studies focused on family structure (21). As a result of financial and time constraints, children of single mothers were suggested to be less physically active and more often fed a low-quality diet (21). It might be that in most studies, including the current one, single motherhood in itself was not a significant risk factor, as physical activity and diet were accounted for in the analyses. Nevertheless, single mothers of older age might, for example, be less challenged by financial constraints as compared with younger single mothers.

Children of families having an income lower than the average household income in the study area were at increased risk of developing overweight. Dubois et al. (8) and Brophy et al. (14) describe a similar effect for preschool children being raised in middle-income or poor families. Other studies focused on parental education as a measure of socioeconomic status. Low parental educational level was associated with a higher BMI $(5,9)$. In our study, after adding household income to the model, low maternal educational level was only a borderline significant risk factor. Low socioeconomic status reduces financial possibilities and may precede overweight development as a result of living in deprived areas, lower health-related knowledge, and adverse overweight-related behavior (22).

In our population, preschool overweight risk was higher in females than in males. This is in agreement with the results in preschool children (7) and older children $(10,12)$. However, it was not reported by all studies $(6,11,13)$. Our results correspond to the higher overweight prevalence among Dutch females as compared with Dutch males in the age range of 3-6 y (18). Because this dissimilarity in overweight prevalence between boys and girls attenuates with age and differs between ethnic groups, a direct comparison of these results between countries is complicated.

We found that the introduction of solid foods after the age of 6 mo was associated with a lower risk of preschool overweight. Likewise, Brophy et al. (14) suggested that the introduction of solids before the age of 3 mo increased the risk of obesity. In the study by Reilly et al. (11), early introduction of solids seemed to increase the risk of obesity in univariable analysis but not in simultaneous analysis. A recent systematic review reported that the timing of introduction of solids and obesity risk in later life are not clearly associated (23).
Studying this association is challenged by methodological issues; however, given that promotion of delaying the introduction of solids is a simple and low-cost act, further study may be warranted (24).

Higher intake of PUFAs at the age of 14 mo was associated with a lower risk of preschool overweight. This specific risk factor was not studied in previous studies simultaneously assessing other risk factors for overweight. However, mounting evidence from studies assessing the influence of PUFA on lipid metabolism suggests a fat-lowering effect of n-3 PUFA intake. The n-3 PUFAs were found to exert their fat-lowering effect through regulation of lipid metabolism by promoting lipolysis and fatty acid oxidation and by inhibiting lipogenesis (25). Research on the influence of n-3 PUFA in infant diet, which currently is lacking, is needed to confirm our findings.

In contrast to several other studies, we did not find an association of infant lifestyle-related risk factors with preschool overweight, such as nighttime sleep duration (11) or TV watching $(5,7,11-13)$. It might be that our study population is too young to adequately measure these risk factors or that these factors are dependent on other stronger risk factors of preschool overweight.

\section{Conclusion}

In a Dutch population-based cohort, several early-life risk factors were independently associated with preschool overweight. Besides previously identified risk factors, we found evidence for an independent role of fetal growth rate and infant dietary PUFA intake. Further research is needed to develop prediction models on the basis of these determinants for risk stratification in overweight prevention at a very young age.

\section{METHODS}

\section{Study Design}

This study was embedded in the Generation R Study, a populationbased prospective cohort study from fetal life onward in Rotterdam, The Netherlands (26). The study was conducted according to the

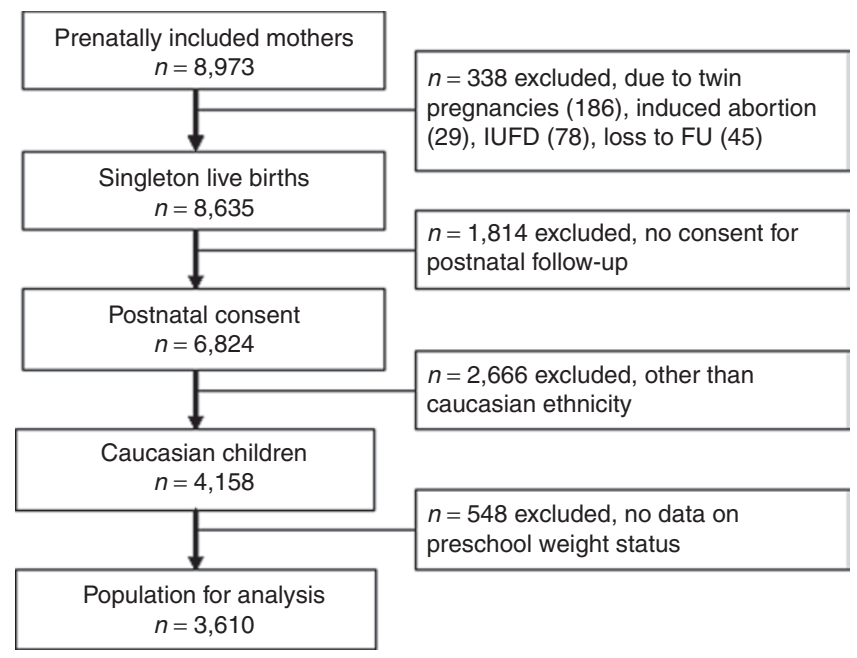

Figure 1. Flowchart of participants included for analysis, the Generation R Study, Rotterdam, the Netherlands. FU, follow-up; IUFD, intrauterine fetal death. 
guidelines of the Helsinki Declaration and approved by the Medical Ethics Committee of the Erasmus Medical Center, Rotterdam. Written informed consent was obtained from all mothers. Of all eligible children in the study area, $61 \%$ participated at birth in the study. Figure 1 shows a flowchart of the study.

\section{Maternal Risk Factors}

Sociodemographic risk factors. Information about maternal age, parity, education, marital status, and family household income was obtained by questionnaire at the time of enrollment into the study (26). We categorized the highest level of achieved education, according to the Dutch standard classification, as follows: "low education," "mid-low/mid-high education," or "higher education" (22). Marital status was dichotomized into "single motherhood" or "no single motherhood." Household income was dichotomized into " $<€ 2,200$ (US \$2,855) per month" or " $\geq € 2,200$ per month," which is the average income per household in the study area (17).

Anthropometrics. We measured maternal anthropometrics, without shoes and heavy clothing, in each trimester at the research center. Information about maternal weight before pregnancy was obtained by questionnaire. BMI was calculated in $\mathrm{kg} / \mathrm{m}^{2}$. We defined weight gain by an increase in weight per week from prepregnancy until the third trimester.

Lifestyle-related risk factors. We assessed maternal smoking and alcohol use in the first, second, and third trimester of pregnancy by questionnaires (27). On the basis of the answers from the repeated questionnaires, we categorized smoking and alcohol use during pregnancy into "no" and "yes" categories. Maternal use of folic acid supplements was assessed by questionnaire at the time of enrollment into the study and categorized into "no" and "yes" categories (28).

Nutrition. We assessed maternal dietary intake at enrollment in the study using a modified version of a validated semiquantitative food frequency questionnaire (FFQ) (29). This FFQ consisted of 293 food items and considered dietary intakes over the previous 3 mo, thereby generally covering the first trimester of pregnancy.

\section{Paternal Risk Factors}

Anthropometrics. Paternal anthropometrics were measured, without shoes and heavy clothing, at the research center at intake, and BMI $\left(\mathrm{kg} / \mathrm{m}^{2}\right)$ was calculated.

Lifestyle-related risk factors. Paternal smoking was assessed by a questionnaire that was filled in by the mother at the time of enrollment into the study (27).

\section{Fetal and Infant Risk Factors}

Fetal growth. We measured head circumference, abdominal circumference, and femur length in the second trimester (median: $20.5 \mathrm{wk}$ of gestation, interquartile range (IQR): $1.3 \mathrm{wk}$ ) and third trimester (median: 30.4 wk of gestation, IQR: $1.1 \mathrm{wk}$ ) of pregnancy using ultrasound (30). Estimated fetal weight was calculated by the formula of Hadlock (31). SD scores adjusted for gestational age at measurement were calculated using reference growth curves from the whole study population (30). We calculated second- and third-trimester fetal growth rate by the change in SD scores between the second and third trimester or between the third trimester and birth. In accordance with an earlier study within the Generation R Study, a decrease or increase in estimated fetal weight greater than $0.67 \mathrm{SD}$ was considered decelerated or accelerated growth, respectively (32).

Infant growth. Information about offspring sex, gestational age, and weight at birth was obtained from medical records and hospital registries. Postnatal growth was routinely measured at the community health centers. Sex- and age-adjusted SD scores were calculated using Growth Analyser (Growth Analyser 3.5, http://www.growthanalyser.org, Dutch Growth Research Foundation) (33). In accordance with earlier studies, a decrease or increase in weight greater than $0.67 \mathrm{SD}$ at birth and the age of $2 \mathrm{y}$ was considered postnatal decelerated or accelerated growth $(8,11,12)$.
Nutrition. Information about breast-feeding was obtained from questionnaires at 2, 6, and 12 mo and about introduction of solid foods at 6 and 12 mo. We assessed the child's nutrition around the age of 14 mo using a modified version of a validated semiquantitative FFQ (34) consisting of 211 food items. The FFQ has been validated against 3-d 24-h recalls in Dutch children aged 14 mo, with the following intraclass correlation coefficients for macronutrients: total energy, 0.4 ; total protein, 0.7 ; total fat, 0.4 ; and carbohydrates, 0.4 . This FFQ was implemented in a later stage in the study and was therefore available in a subgroup of participants (71\%). Questionnaires were filled in by the primary caregiver.

Activity and leisure time. Information about nighttime sleep duration (hours/night), attending day care (never, $<8,8-16,16-24,14-32$, or $>32 \mathrm{~h} / \mathrm{wk}$ ), and TV watching during the week (never, $<0.5,0.5-1$, or $>1 \mathrm{~h} / \mathrm{d}$ ) and weekend (never, $<1,1-2$, or $>2 \mathrm{~h} / \mathrm{d}$ ) was collected by questionnaires at the age of $2 \mathrm{y}$. Questionnaires were filled in by the primary caregiver. Nighttime sleep duration was dichotomized into " $<11.5 \mathrm{~h} /$ night" and " $\geq 11.5 \mathrm{~h} /$ night," because according to the American Academy of Pediatrics, $11.5 \mathrm{~h}$ is the mean nighttime sleep duration at the age of $2 y$ (35). We summed TV watching during the week and weekend. According to the American Academy of Pediatrics, TV watching until the age of $2 \mathrm{y}$ is not recommended. Therefore, we categorized TV watching into "never" and "yes" categories (36). Preschool children in the Netherlands attending day care, on average, spend $25 \mathrm{~h} / \mathrm{wk}$ in day care (37). Therefore, we categorized day care use into " $\leq 24 \mathrm{~h} / \mathrm{wk}$ " and ">24h/wk."

\section{Overweight}

Height and weight were routinely measured by well-trained staff in community health centers. We aimed to measure the height and weight of all children before, but close to the age of $4 \mathrm{y}$. This is the age at which children enter primary school in the Netherlands. The median age of the measurements was 3.8 y (IQR: $0.8 \mathrm{y})$. BMI $\left(\mathrm{kg} / \mathrm{m}^{2}\right)$ was calculated. Overweight (including obesity) was defined on the basis of the international growth charts presented by the International Obesity Taskforce (38).

\section{Statistical Analysis}

We used $t$-tests and $\chi^{2}$ tests to compare maternal, paternal, fetal, and infant characteristics between nonoverweight and overweight participants. We performed univariate logistic regression models to assess the associations of the putative risk factors with preschool overweight. We explored interactions among parental, fetal, and infant risk factors that were biologically plausible by adding a multiplicative term to the univariate logistic regression models. Subsequently, we included all putative risk factors and significant interactions $(P<0.10)$ simultaneously in a multiple logistic regression model. To take the time difference between fetal growth measurements into account, we additionally included the time difference between the time points of the measurements as a variable to the model. To identify the most significant independent risk factors, we performed logistic regression using backward selection $(P$ $<0.10$ ). To explore the effect of the interactions that remained in the model, we stratified the analysis by these risk factors. Because total daily energy intake is strongly correlated with daily macronutrient intake, we used the energy partition method to adjust macronutrient intake for total energy intake (39). We explored the effect of multiple testing by Bonferroni correction. To prevent bias associated with missing data, risk factors with missing values were multiple imputed (five imputations) on the basis of the correlation of the missing variables with other patient characteristics, according to the Markov chain Monte Carlo method (40). The amount of missing values ranged from $1 \%$ to $23 \%$, with the exception of the dietary intakes at the age of 14 mo (40\%), which is because of the initiation of this data collection at a later stage in the study (response was 85\%). Results are reported as ORs and 95\% CIs. $P$ values are two sided. Analyses were performed using the Predictive Analytic Software version 17.0 for Windows (PASW, Chicago, IL).

\section{STATEMENT OF FINANCIAL SUPPORT}

The Generation R Study is conducted by the Erasmus Medical Center in close collaboration with the School of Law and the Faculty of Social Sciences at Erasmus University, Rotterdam; the Municipal Health Service, Rotterdam 
area; and the Stichting Trombosedienst \& Artsenlaboratorium Rijnmond (Star-MDC), Rotterdam. The general design of the Generation R Study was made possible by financial support from the Erasmus Medical Center, Rotterdam; the Erasmus University, Rotterdam; the Dutch Ministry of Health, Welfare and Sport; and the Netherlands Organization for Health Research and Development (ZonMw). V.W.V.J. received an additional grant from the Netherlands Organization for Health Research and Development (ZonMw grant $90700303,916.10159)$.

\section{ACKNOWLEDGMENTS}

The authors gratefully acknowledge the contribution of participants and assistance of general practitioners, hospitals, midwives, and pharmacies in Rotterdam.

\section{REFERENCES}

1. James WP. WHO recognition of the global obesity epidemic. Int J Obes (Lond) 2008;32:Suppl 7:S120-6.

2. Reilly JJ, Kelly J. Long-term impact of overweight and obesity in childhood and adolescence on morbidity and premature mortality in adulthood: systematic review. Int J Obes (Lond) 2011;35:891-8.

3. Bayer $\mathrm{O}$, Krüger H, von Kries R, Toschke AM. Factors associated with tracking of BMI: a meta-regression analysis on BMI tracking. Obesity (Silver Spring) 2011;19:1069-76.

4. Monasta L, Batty GD, Cattaneo A, et al. Early-life determinants of overweight and obesity: a review of systematic reviews. Obes Rev 2010;11:695-708.

5. Beyerlein A, Toschke AM, von Kries R. Risk factors for childhood overweight: shift of the mean body mass index and shift of the upper percentiles: results from a cross-sectional study. Int J Obes (Lond) 2010;34:642-8.

6. Kitsantas P, Gaffney KF. Risk profiles for overweight/obesity among preschoolers. Early Hum Dev 2010;86:563-8.

7. Jouret B, Ahluwalia N, Cristini C, et al. Factors associated with overweight in preschool-age children in southwestern France. Am J Clin Nutr 2007;85:1643-9.

8. Dubois L, Girard M. Early determinants of overweight at 4.5 years in a population-based longitudinal study. Int J Obes (Lond) 2006;30:610-7.

9. Huus K, Ludvigsson JF, Enskär K, Ludvigsson J. Risk factors in childhood obesity-findings from the All Babies In Southeast Sweden (ABIS) cohort. Acta Paediatr 2007;96:1321-5.

10. Júlíusson PB, Eide GE, Roelants M, Waaler PE, Hauspie R, Bjerknes R. Overweight and obesity in Norwegian children: prevalence and sociodemographic risk factors. Acta Paediatr 2010;99:900-5.

11. Reilly JJ, Armstrong J, Dorosty AR, et al. Early life risk factors for obesity in childhood: cohort study. BMJ 2005;330:1357.

12. Blair NJ, Thompson JM, Black PN, et al. Risk factors for obesity in 7-yearold European children: the Auckland Birthweight Collaborative Study. Arch Dis Child 2007;92:866-71.

13. Kuhle S, Allen AC, Veugelers PJ. Perinatal and childhood risk factors for overweight in a provincial sample of Canadian Grade 5 students. Int J Pediatr Obes 2010;5:88-96.

14. Brophy S, Cooksey R, Gravenor MB, et al. Risk factors for childhood obesity at age 5: analysis of the millennium cohort study. BMC Public Health 2009;9:467.

15. Mook-Kanamori DO, Durmus B, Sovio U, et al. Fetal and infant growth and the risk of obesity during early childhood: the Generation R Study. Eur J Endocrinol 2011;165:623-30.

16. Ay L, Van Houten VA, Steegers EA, et al. Fetal and postnatal growth and body composition at 6 months of age. J Clin Endocrinol Metab 2009;94:2023-30.

17. Centrum voor Onderzoek en Statistiek (Centre for Research and Statistics). (http://www.rotterdam.nl/onderzoek). 2005. Rotterdam, The Netherlands.

18. de Wilde JA, van Dommelen P, Middelkoop BJ, Verkerk PH. Trends in overweight and obesity prevalence in Dutch, Turkish, Moroccan and Surinamese South Asian children in the Netherlands. Arch Dis Child 2009;94:795-800
19. Pilgaard K, Hammershaimb Mosbech T, Grunnet L, et al. Differential nongenetic impact of birth weight versus third-trimester growth velocity on glucose metabolism and magnetic resonance imaging abdominal obesity in young healthy twins. J Clin Endocrinol Metab 2011;96:2835-43.

20. Morrison JL, Duffield JA, Muhlhausler BS, Gentili S, McMillen IC. Fetal growth restriction, catch-up growth and the early origins of insulin resistance and visceral obesity. Pediatr Nephrol 2010;25:669-77.

21. Byrne LK, Cook KE, Skouteris H, Do M. Parental status and childhood obesity in Australia. Int J Pediatr Obes 2011;6:415-8.

22. van Rossem L, Silva LM, Hokken-Koelega A, et al. Socioeconomic status is not inversely associated with overweight in preschool children. J Pediatr 2010;157:929-935.e1.

23. Moorcroft KE, Marshall JL, McCormick FM. Association between timing of introducing solid foods and obesity in infancy and childhood: a systematic review. Matern Child Nutr 2011;7:3-26.

24. Seach KA, Dharmage SC, Lowe AJ, Dixon JB. Delayed introduction of solid feeding reduces child overweight and obesity at 10 years. Int $J$ Obes (Lond) 2010;34:1475-9.

25. Tai CC, Ding ST. N-3 polyunsaturated fatty acids regulate lipid metabolism through several inflammation mediators: mechanisms and implications for obesity prevention. J Nutr Biochem 2010;21:357-63.

26. Jaddoe VW, van Duijn CM, van der Heijden AJ, et al. The Generation R Study: design and cohort update 2010. Eur J Epidemiol 2010;25:823-41.

27. Durmus B, Kruithof CJ, Gillman MH, et al. Parental smoking during pregnancy, early growth, and risk of obesity in preschool children: the Generation R Study. Am J Clin Nutr 2011;94:164-71.

28. Timmermans S, Jaddoe VW, Hofman A, Steegers-Theunissen RP, Steegers EA. Periconception folic acid supplementation, fetal growth and the risks of low birth weight and preterm birth: the Generation R Study. Br J Nutr 2009;102:777-85.

29. Klipstein-Grobusch K, den Breeijen JH, Goldbohm RA, et al. Dietary assessment in the elderly: validation of a semiquantitative food frequency questionnaire. Eur J Clin Nutr 1998;52:588-96.

30. Verburg BO, Steegers EA, De Ridder M, et al. New charts for ultrasound dating of pregnancy and assessment of fetal growth: longitudinal data from a population-based cohort study. Ultrasound Obstet Gynecol 2008;31:388-96.

31. Hadlock FP, Harrist RB, Sharman RS, Deter RL, Park SK. Estimation of fetal weight with the use of head, body, and femur measurements-a prospective study. Am J Obstet Gynecol 1985;151:333-7.

32. Sonnenschein-van der Voort AM, Jaddoe VW, Raat H, et al. Fetal and infant growth and asthma symptoms in preschool children: the Generation R Study. Am J Respir Crit Care Med 2012;185:731-7.

33. Niklasson A, Ericson A, Fryer JG, Karlberg J, Lawrence C, Karlberg P. An update of the Swedish reference standards for weight, length and head circumference at birth for given gestational age (1977-1981). Acta Paediatr Scand 1991;80:756-62.

34. Feunekes GI, Van Staveren WA, De Vries JH, Burema J, Hautvast JG. Relative and biomarker-based validity of a food-frequency questionnaire estimating intake of fats and cholesterol. Am J Clin Nutr 1993;58:489-96.

35. Iglowstein I, Jenni OG, Molinari L, Largo RH. Sleep duration from infancy to adolescence: reference values and generational trends. Pediatrics 2003;111:302-7.

36. American Academy of Pediatrics. Committee on Public Education. American Academy of Pediatrics: Children, adolescents, and television. Pediatrics 2001;107:423-6.

37. Statistics Netherlands (Centraal Bureau voor Statistiek). Labor force survey '09 (Enquête Beroepsbevolking '09). Heerlen, the Netherlands: http://www. cbs.nl, 2009.

38. Cole TJ, Bellizzi MC, Flegal KM, Dietz WH. Establishing a standard definition for child overweight and obesity worldwide: international survey. BMJ 2000;320:1240-3.

39. Willett WC, Howe GR, Kushi LH. Adjustment for total energy intake in epidemiologic studies. Am J Clin Nutr 1997;65:Suppl 4:1220S-1228S; discussion 1229S-1231S.

40. Sterne JA, White IR, Carlin JB, et al. Multiple imputation for missing data in epidemiological and clinical research: potential and pitfalls. BMJ 2009;338:b2393. 